pendent on irrigation derived from the water of glacier-fed rivers, which, if not artificially caught, rapidly disappears in the sand. This absence of atmospheric moisture is due to the immense distance which separates this region from the sea, and the high mountains which intervene on all sides.

The importance of the Tarim Basin lies in the fact that it was in the direct line of communication which once formed the great trade route between China and the West. Two thousand years ago it seems to have been the only means of interchange of commerce between the Far East and the West. Not only does the shortest route lie along it, but also the way to the north was barred by the presence of the fierce and warlike Huns and the Tien Shan Range, while to the south the snow-clad mountains of Tibet and the Himalayas formed an impenetrable barrier. Formidable as the passage of such a desert must have been, it appears to have presented less difficulties to the Chinese than were likely to be encountered on any alternative route. These circumstances accounted for the control China found it necessary to assume over this far-extended line, which eventually reached to the Pamirs. This was at first of a political nature, but ended in complete military occupation lasting for a thousand years. Sir Aurel Stein has been able to trace over a long distance the remains of the old Limes, or defensive wall, erected at the end of the second century B.C., no doubt the ancient representative of our modern line of block-houses.

The reasons for the abandonment of such a route as this, and the evacuation of the former inhabitants, give rise to interesting speculation. Was it due to an alteration of climate bringing about excessive desiccation, or to some other cause? From the high state of preservation of records, and other materials, discovered by Sir Aurel, it would appear that the climate has not altered and is much the same now as it was 2000 years ago, for such friable objects as were found could only stand the test of time in an extremely arid climate. If, then, the occupation of this area was independent of climate, it must have been dependent on irrigation, which in its turn was dependent on water derived from glacier-fed rivers.

The lecturer discovered several abandoned sites of human habitation which had been maintained by irrigation, but are now far distant from the terminal point of the river which formerly supplied them with water. This seems to show, as originally suggested by Sir Sidney Burrard, that the evacuation of this area was due to the diminution of water in the rivers and not to an alteration of climate, of which there is no evidence. The glaciers, probably the remains of a former ice-age, are known to be shrinking, with the consequent decrease of the water supply, which probably accounted for the abandonment of this important commercial highway. But while this seems to afford an explanation, it is not safe to rely entirely on it, as there is always the human element to be taken into account, and that is not so easy to gauge. The way in which the Chinese have held this region, throughout the long years of varied history, is a remarkable testimony to their tenacity of purpose. On more than one occasion it has been lost, generally on account of internal dissensions, only to be regained in more settled times, and is held down to the present day.

It is to be hoped that at some future time Sir Aurel Stein will give us some details of the contents of the documents he has found, and of other objects of interest. We may add that he was accompanied on his expeditions by surveyors of the Indian Survey, and that a series of maps on a scale of $x / 500,000$, and I inch to 4 miles, have been produced by that department as the result of his surveys. H. L. C.

\title{
Tropical Medicine in the Southern United States.
}

THE recent Conference on Tropical Problems at Kingston, Jamaica, has served to direct attention to the enormous interest which is taken at the present time in tropical medicine and allied sciences in the United States. This movement may be said to have started some thirty years ago when the States had to take control of the Philippine and Cuba Islands after the Spanish War; it became greater when it was decided to open the Panama Canal. The building of the canal was rendered possible by the genius of Gorgas, who applied in a practical way the discoveries of Ross and Manson. The scourges of yellow fever and malaria which had caused the complete failure of the French effort were successfully combated, and the canal was built.

A very important feature of the moment is that private concerns and corporations with estates and financial interests in the tropical zone are taking great interest in tropical medical problems. Some of these concerns have complete medical services of their own. The United States Fruit Company, for example, has a tropical medical service admirably organised, with branches in several Central American countries, Guatemala, Costa Rica, Honduras, etc. At the head of each branch or division there is a principal medical officer with an adequate medical and nursing staff in each division. The Company has built one of several up-to-date hospitals with splendid laboratories, X-ray departments, etc. Some of these hospitals are magnificent, and would adorn any big European or American city.

Several United States universities, as, for example,
Harvard, established departments of tropical medicine some years ago. Funds have been collected now to found a large and up-to-date tropical school at New Orleans, and to institute a professorship of tropical medicine at the University of that city.

New Orleans certainly seems to be from every point of view the ideal place for such a school; it is in one of the most southern parts of the States (Louisiana), and tropical diseases are far from scarce there; yellow fever used to be a scourge in Louisiana and other southern United States, and malaria is still common. It has intimate trade relations with Cuba, Mexico, and Central and Southern America. It has the most famous university (Tulane) in the south, and modern progressive scientific institutes.

The authorities of Tulane University have offered the university professorship and the directorship of the new school to Dr. Aldo Castellani, lecturer at the London School of Tropical Medicine and Director of Tropical Medicine at the Ross Institute. Dr. Castellani is known by his discoveries in connexion with sleeping sickness, yaws, and several other tropical diseases. It may also be remembered that it was Dr. Castellani who, some years before the War, devised and prepared the combined typhoid + paratyphoid, and the typhoid + paratyphoid + cholera vaccines which, after much discussion, were generally adopted by all the allied armies, instead of the simple typhoid vaccination. He has written jointly with Dr. Albert J. Chalmers a standard text-book on tropical medicine, which has run already into three editions.

No. 2874 , VOL. I I 4 ] 